Brazilian Journal

of Chemical

Engineering

\title{
THERMOPHYSICAL PROPERTIES OF 1-ETHYL-3-METHYLIMIDAZOLIUM CHLORIDE SOLUTION FROM 293.15 TO 323.15 K
}

\author{
Olga R. R. Gandolfi ${ }^{1}$, Gabriel R. F. Gonçalves ${ }^{1}$, Juliana G. Pimentel ${ }^{1}$, \\ Rafael C. I. Fontan ${ }^{1}$, Evaldo C. S. Júnior ${ }^{1}$, Paulo Bonomo ${ }^{1}$, \\ Claúdia L. R. Barreto ${ }^{1}$, Cristiane M. Veloso ${ }^{1}$ and Renata C. F. Bonomo ${ }^{1 *}$ \\ ${ }^{1}$ Universidade Estadual do Sudoeste da Bahia, Departamento de Tecnologia Animal e Rural, Laboratório de Engenharia de Processos, \\ Itapetinga, BA, Brasil. E-mail: bonomorcf@yahoo.com.br, 0000-0002-9896-4099
}

(Submitted: March 20, 2018 ; Revised: May 21, 2018 ; Accepted: June 16, 2018)

\begin{abstract}
Aqueous systems composed of ionic liquid make up a new alternative for use in processes involving the separation of biomolecules. The objective of this experiment was to obtain the thermo-physical properties of density, refractive index, electrical conductivity, molar volume, thermal expansion coefficient and apparent specific volume of the ionic liquid 1-ethyl-3-methylimidazolium chloride. The thermo-physical properties of aqueous solutions of this ionic liquid were measured as a function of the mass fraction $\mathrm{w}=(0.05$, $0.125,0.2,0.275$ and 0.35$)$, temperature $\mathrm{T}=(293.15,303.15,313.15$ and 323.15$) \mathrm{K}$ and $\mathrm{pH}=(7.5,8.0$ and 8.5). Models representing the combined effects between variables were fit since they are required for industrial applications where the physical parameters must be accurately calculated. Models representing the combined effects of the variables temperature, mass fraction and $\mathrm{pH}$ values of ionic liquid were adjusted and presented good fit.
\end{abstract}

Keywords: Thermodynamic properties; Binary mixtures; Ionic liquid; Models.

\section{INTRODUCTION}

Ionic liquids (ILs) are organic salts which have a low melting point. They have unique physicalchemical properties, with negligible vapor pressure, non-flammable, non-explosive, electrochemically and thermally stable, and can be easily recycled. These salts present extremely low vapor pressures, and this feature has attracted attention given their potential as solvents to replace volatile organic solvents for a large variety of chemical reactions, separation processes and other applications. Such compounds have many favorable properties which make them attractive for many applications (Ficke et al. 2010; França et al. 2009; Muhammad et al. 2012).

Due to these characteristics, the ILs have been extensively studied in two-phase aqueous systems
(ATPS). These systems consist of two aqueous phases rich in two structurally different compounds which are immiscible, where they separate into two phases above certain concentration values. The ATPS may be formed from polymer, surfactant and salt, which may be strategically combined to achieve high selectivity and efficiency for the extraction and purification of biomolecules (Vicente et al., 2014). However, most polymers used to form the phases have high viscosity and form turbid solutions, interfering in determination of the analytes. In recent years it has been demonstrated that ionic liquids are a viable alternative for ATPS composed of common polymers since they present unique advantages, such as low viscosity, formation of emulsion, absence of volatile organic solvents, rapid phase separation and high extraction efficiency (Yan et al., 2014).

\footnotetext{
* Corresponding author: Renata C. F. Bonomo - E-mail: bonomorcf@yahoo.com.br
} 
The ATPS formed by ionic liquid have been successfully applied to separate, concentrate, isolate and purify biocompounds. Several studies with ILs have been published in recent years, including their application in complete removal of dyes, recovery of antibiotics, ethanol and butanol from fermentation broth, acetone, removal of organic contaminants from aqueous waste streams and protein partitioning (Ferreira et al., 2014; Huddleston et al., 1998; Fadeev and Meagher, 2001; Du et al., 2007; Dreyer et al., 2009). For these reasons, predicting the basic thermophysical properties of the phase forming systems at various concentrations and temperatures is also an indispensable requirement for the design and scale up of a wide range of separation process.

Given the above, the present study sought to evaluate the thermophysical properties of density, thermal expansion coefficient, molar volume, specific volume, refractive index and electrical conductivity of binary mixtures of water +1 -ethyl-3-methylimidazolium chloride in various conditions of $\mathrm{pH}$, temperature and mass fraction.

\section{EXPERIMENTAL SECTION}

\section{Materials}

The 1-ethyl-3-methylimidazolium chloride (CAS: 65039-09-0) was purchased from Sigma Aldrich. Potassium hydroxide (CAS: 1310-58-3) and hydrochloric acid (CAS: 7647-01-0) were purchased from Vetec Fine Chemicals (Brazil) and Synth, respectively. All reagents were of analytical grade and used without further purification. The entire experiment was conducted at the Process Engineering Laboratory of the State University of Southwest Bahia (UESB), Itapetinga campus - Bahia, Brazil.

\section{Methods}

\section{Preparation of solutions}

Aqueous solutions of 1-ethyl-3-methylimidazolium chloride $\left(\left[\mathrm{C}_{2} \mathrm{mim}\right] \mathrm{Cl}\right)$ were prepared using an analytical balance M254A (Bel Engineering) with an accuracy of $\pm 0.0001 \mathrm{~g}$. Stock solutions of 1-ethyl-3methylimidazolium chloride $(w=0.50)$ were prepared for each $\mathrm{pH}$ value $(7.5,8.0$ and 8.5$)$ by addition of hydrochloric acid or potassium hydroxide when required. These $\mathrm{pH}$ values were chosen because they are commonly used in ATPS for separation of biomolecules (Sampaio et al., 2017). Appropriate quantities of the stock solution were diluted in tubes and shaken manually to obtain the desired mass fraction $\mathrm{w}$ $=(0.05,0.125,0.2,0.275$ and 0.35$)$. The analyses were performed at temperatures of $\mathrm{T}=(293.15,303.15$, 313.15 and 323.15) K, in all prepared solutions. Distilled water was used in all the experiments.

\section{Density}

The densities of the solutions were determined using a Bench Digital densimeter DMA 5000M (Anton Paar) with accuracy of $\pm 5 \times 10^{-6} \mathrm{~g}^{\cdot} \mathrm{cm}^{-3}$ and repeatability of $\pm 1 \times 10^{-6}{\mathrm{~g} \cdot \mathrm{cm}^{-3}}^{-3}$ in the operating

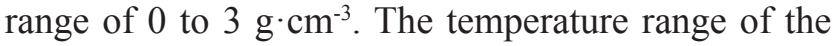
equipment is $273.15 \mathrm{~K}$ to $363.15 \mathrm{~K}$ with an accuracy of $\pm 0.01 \mathrm{~K}$ and repeatability of $\pm 0.001 \mathrm{~K}$.

\section{Refractive Index}

For the refractive index, the digital refractometer Q767BD (Quimis) was used with accuracy of \pm 0.0002 and wavelength of 589 nanometers, as is conventionally done. This device was connected to a thermostatic bath (Tecnal, Te-184), allowing for temperature control with an accuracy of $0.1 \mathrm{~K}$. The equipment was calibrated with distilled water at the studied temperature, and the sample was then placed in the prism of the refractometer for direct reading.

\section{Electrical conductivity}

Electrical conductivity was determined using a bench digital conductivity meter Q795m (Quimis) with a precision of $0.5 \%$. The equipment was calibrated with a standard $0.01 \mathrm{M} \mathrm{KCl}$ solution. The temperature of the samples was controlled in a thermostatic bath (Tecnal, Te-184), allowing for temperature control to within $0.1 \mathrm{~K}$.

\section{Molar Volume}

The molar volume $\left(V_{m}\right)$ is the volume occupied by one mole of a substance at a fixed temperature and pressure. The $V_{m}$ of the binary mixtures of water + 1-ethyl-3-methylimidazolium chloride was calculated using the following equation:

$$
\mathrm{V}_{\mathrm{m}}=\frac{\mathrm{M}}{\rho}
$$

where: $M$ is the molecular mass in $\mathrm{g} \cdot \mathrm{mol}^{-1}, \rho$ is the density in $\mathrm{g} \cdot \mathrm{cm}^{-3}$ and $V_{m}$ is the molar volume $\mathrm{cm}^{3} \cdot \mathrm{mol}^{-1}$.

\section{Thermal Expansion Coefficient}

The density calculated for the binary mixtures of water + 1-ethyl-3-methylimidazolium chloride was used to calculate the thermal expansion coefficient $\left(\alpha_{p}\right)$, using the following equation:

$\alpha_{p}=-\frac{1}{\rho}\left(\frac{\partial \rho}{\partial T}\right)_{p}$

where: $\rho$ is the density obtained in $\mathrm{g} \cdot \mathrm{cm}^{-3}$.

\section{Apparent specific volume}

The apparent specific volume $\left(\mathrm{v}_{2 \varnothing}\right)$ was calculated from the density data using equation 3 : 


$$
\mathrm{v}_{2 \varnothing}=\frac{1}{\rho}\left[1+\frac{\rho_{0}-\rho}{\mathrm{w} \rho_{0}}\right]
$$

where: $\rho\left(\mathrm{g} \cdot \mathrm{cm}^{-3}\right)$ and $\rho_{0}\left(\mathrm{~g} \cdot \mathrm{cm}^{-3}\right)$ are the densities of the ionic solution and pure water, respectively.

\section{Statistical analysis}

All statistical analyses were performed using SAEG v.9.1 (Ribeiro Júnior, 2001). The experiment was conducted in a completely randomized design (CRD) with two replications and in triplicate. The experimental data obtained was fitted to polynomial models, where the correlation coefficient was calculated for the treatment means. Correlation coefficients between the predicted and real values were calculated for all models. The standard deviation for each property was also calculated. All analyses were performed considering a 5\% significance level. The expanded uncertainties in density, refractive index, electrical conductivity, molar volume, apparent specific volume and thermal expansion coefficient were calculated as combined uncertainties multiplied by 2 . The coverage factor of 2 yields a $95 \%$ confidence interval.

\section{RESULTS AND DISCUSSION}

\section{Density, refractive index and electrical conductivity of the binary mixtures}

The density, refractive index and electrical conductivity of ionic liquid solutions were measured at different temperatures $\mathrm{T}=(293.15,303.15,313.15$ and 323.15$) \mathrm{K}, \mathrm{pH}$ values $(7.5,8.0$ and 8.5) and mass fraction $\mathrm{w}=(0.05,0.12,0.2,0.275$ and 0.35$)$. Table 1 shows the mean and standard deviation of these properties in all conditions studied.

Figures 1,2 and 3 shows the mean of these properties in all conditions studied. The density, refractive index and electrical conductivity of the binary mixtures of water + 1-ethyl-3-methylimidazolium chloride increased with increasing mass fraction of the ionic liquid and decreased with the increase in temperature at each $\mathrm{pH}$ condition studied. Muray et al. (2013) observed similar behavior, studying thermo-physical properties of ionic liquid imidazolium base. Similar behavior for density was found by Rafie et al. (2016) studying the volumetric properties of ionic liquids in sucrose aqueous solution at different temperatures and ambient pressure.

The decrease in density with increasing temperature can be due to the increased mobility of liquid molecules from the increase in thermal energy, making the interactions within the system weaker and causing the volume expansion and reducing the density (Siongco et al., 2013). Figure 4 shows the comparison of measured densities for the (1-ethyl-3methylimidazolium chloride + water) binary system in this work at different $\mathrm{pH}$ values and the literature at $\mathrm{T}=$ $303.15 \mathrm{~K}$. This discrepancy in slopes may come from differences in values of $\mathrm{pH}$ and also small differences in the densities due to pressure.

Similar behavior can be observed for the index of refraction for all mass fractions of 1-ethyl-3-

Table 1. Density $(\rho)$, refractive index $\left(n_{D}\right)$ and conductivity $(\kappa)$ of the binary mixtures of water +1 -ethyl-3methylimidazolium chloride at the different mass fraction $(0.05,0.12,0.2,0.275$ and 0.35$)$, temperatures $\mathrm{T}=$ $(293.15,303.15,313.15$ and 323.15$) \mathrm{K}$ and $\mathrm{pH}(7.5,8.0$ and 8.5) .

\begin{tabular}{|c|c|c|c|c|}
\hline $\mathbf{T} / \mathbf{K}$ & $\mathbf{W}$ & $\rho / g \cdot \mathrm{cm}^{-3}$ & $n_{D}$ & $\kappa / 10^{-3} \mathrm{mS} \cdot \mathrm{cm}^{-1}$ \\
\hline & & & & \\
\hline \multirow[t]{5}{*}{293.15} & 0.050 & $1.0039 \pm 0.0001$ & $1.3416 \pm 0.0001$ & $17.5446 \pm 0.7642$ \\
\hline & 0.125 & $1.0130 \pm 0.0001$ & $1.3537 \pm 0.0001$ & $40.6085 \pm 0.3863$ \\
\hline & 0.200 & $1.0242 \pm 0.0001$ & $1.3678 \pm 0.0001$ & $65.0967 \pm 1.5680$ \\
\hline & 0.275 & $1.0355 \pm 0.0001$ & $1.3826 \pm 0.0009$ & $87.4540 \pm 1.8243$ \\
\hline & 0.350 & $1.0476 \pm 0.0004$ & $1.3962 \pm 0.0005$ & $107.8054 \pm 3.0910$ \\
\hline \multirow[t]{5}{*}{303.15} & 0.050 & $1.0000 \pm 0.0001$ & $1.3406 \pm 0.0003$ & $17.6565 \pm 0.5265$ \\
\hline & 0.125 & $1.0099 \pm 0.0001$ & $1.3527 \pm 0.0003$ & $40.5151 \pm 0.5184$ \\
\hline & 0.200 & $1.0205 \pm 0.0001$ & $1.3664 \pm 0.0001$ & $64.8170 \pm 1.4372$ \\
\hline & 0.275 & $1.0313 \pm 0.0001$ & $1.3812 \pm 0.0005$ & $87.2676 \pm 2.3521$ \\
\hline & 0.350 & $1.0430 \pm 0.0004$ & $1.3948 \pm 0.0002$ & $107.3345 \pm 3.4826$ \\
\hline \multirow[t]{5}{*}{313.15} & 0.050 & $0.9966 \pm 0.0001$ & $1.3391 \pm 0.0001$ & $17.4303 \pm 1.2536$ \\
\hline & 0.125 & $1.0057 \pm 0.0001$ & $1.3518 \pm 0.0001$ & $38.1956 \pm 0.1174$ \\
\hline & 0.200 & $1.0162 \pm 0.0001$ & $1.3648 \pm 0.0003$ & $61.6610 \pm 1.2508$ \\
\hline & 0.275 & $1.0266 \pm 0.0002$ & $1.3797 \pm 0.0011$ & $83.1728 \pm 2.1267$ \\
\hline & 0.350 & $1.0380 \pm 0.0004$ & $1.3927 \pm 0.0005$ & $102.9411 \pm 3.4685$ \\
\hline \multirow[t]{5}{*}{323.15} & 0.050 & $0.9926 \pm 0.0001$ & $1.3374 \pm 0.0004$ & $17.9765 \pm 0.9637$ \\
\hline & 0.125 & $1.0002 \pm 0.0001$ & $1.3504 \pm 0.0001$ & $39.6268 \pm 1.1170$ \\
\hline & 0.200 & $1.0111 \pm 0.0005$ & $1.3630 \pm 0.0005$ & $63.7163 \pm 1.3768$ \\
\hline & 0.275 & $1.0214 \pm 0.0002$ & $1.3778 \pm 0.0008$ & $85.8561 \pm 2.6360$ \\
\hline & 0.350 & $1.0326 \pm 0.0004$ & $1.3908 \pm 0.0005$ & $105.9541 \pm 3.6763$ \\
\hline
\end{tabular}


Continued from Table 1

\begin{tabular}{|c|c|c|c|c|}
\hline $\mathbf{T} / \mathrm{K}$ & $\mathbf{w}$ & $\rho / \mathrm{g} \cdot \mathrm{cm}^{-3}$ & $n_{D}$ & $\mathrm{\kappa} / 10^{-3} \mathrm{mS} \cdot \mathrm{cm}^{-1}$ \\
\hline & & & & \\
\hline \multirow[t]{5}{*}{293.15} & 0.050 & $1.0043 \pm 0.0001$ & $1.3414 \pm 0.0001$ & $16.6523 \pm 0.4220$ \\
\hline & 0.125 & $1.0137 \pm 0.0001$ & $1.3535 \pm 0.0001$ & $39.7316 \pm 0.6737$ \\
\hline & 0.200 & $1.0239 \pm 0.0001$ & $1.3676 \pm 0.0001$ & $62.7498 \pm 0.2775$ \\
\hline & 0.275 & $1.0350 \pm 0.0001$ & $1.3812 \pm 0.0001$ & $83.5054 \pm 4.5756$ \\
\hline & 0.350 & $1.0469 \pm 0.0001$ & $1.3954 \pm 0.0001$ & $103.3806 \pm 1.7279$ \\
\hline \multirow{5}{*}{303.15} & 0.050 & $1.0015 \pm 0.0001$ & $1.3404 \pm 0.0001$ & $16.6523 \pm 0.4485$ \\
\hline & 0.125 & $1.0104 \pm 0.0001$ & $1.3522 \pm 0.0001$ & $39.8251 \pm 0.2771$ \\
\hline & 0.200 & $1.0202 \pm 0.0001$ & $1.3663 \pm 0.0001$ & $63.2166 \pm 0.3827$ \\
\hline & 0.275 & $1.0308 \pm 0.0001$ & $1.3797 \pm 0.0001$ & $83.6921 \pm 4.3116$ \\
\hline & 0.350 & $1.0423 \pm 0.0001$ & $1.3938 \pm 0.0001$ & $102.9166 \pm 2.6478$ \\
\hline \multirow[t]{5}{*}{313.15} & 0.050 & $0.9979 \pm 0.0001$ & $1.3388 \pm 0.0002$ & $16.0550 \pm 0.5440$ \\
\hline & 0.125 & $1.0065 \pm 0.0001$ & $1.3513 \pm 0.0001$ & $38.4293 \pm 0.6457$ \\
\hline & 0.200 & $1.0159 \pm 0.0001$ & $1.3647 \pm 0.0001$ & $60.4849 \pm 0.0129$ \\
\hline & 0.275 & $1.0262 \pm 0.0001$ & $1.3780 \pm 0.0003$ & $79.3894 \pm 3.7525$ \\
\hline & 0.350 & $1.0373 \pm 0.0001$ & $1.3919 \pm 0.0005$ & $98.6143 \pm 2.0328$ \\
\hline \multirow[t]{5}{*}{323.15} & 0.050 & $0.9934 \pm 0.0001$ & $1.3375 \pm 0.0004$ & $16.7187 \pm 0.3161$ \\
\hline & 0.125 & $1.0020 \pm 0.0001$ & $1.3498 \pm 0.0001$ & $39.8625 \pm 0.6461$ \\
\hline & 0.200 & $1.0111 \pm 0.0001$ & $1.3631 \pm 0.0004$ & $62.4534 \pm 0.5195$ \\
\hline & 0.275 & $1.0210 \pm 0.0002$ & $1.3761 \pm 0.0006$ & $82.2503 \pm 3.7510$ \\
\hline & 0.350 & $1.0320 \pm 0.0001$ & $1.3893 \pm 0.0001$ & $101.9130 \pm 1.9156$ \\
\hline \multirow{6}{*}{293.15} & & & & \\
\hline & 0.050 & $1.0048 \pm 0.0002$ & $1.3414 \pm 0.0001$ & $16.6693 \pm 0.1053$ \\
\hline & 0.125 & $1.0143 \pm 0.0001$ & $1.3542 \pm 0.0001$ & $40.3545 \pm 0.4767$ \\
\hline & 0.200 & $1.0252 \pm 0.0001$ & $1.3688 \pm 0.0001$ & $59.9509 \pm 0.7293$ \\
\hline & 0.275 & $1.0367 \pm 0.0002$ & $1.3830 \pm 0.0001$ & $81.6592 \pm 0.0442$ \\
\hline & 0.350 & $1.0494 \pm 0.0001$ & $1.3981 \pm 0.0001$ & $102.4296 \pm 0.0442$ \\
\hline \multirow[t]{5}{*}{303.15} & 0.050 & $1.0019 \pm 0.0002$ & $1.3404 \pm 0.0001$ & $16.6959 \pm 1.6150$ \\
\hline & 0.125 & $1.0110 \pm 0.0001$ & $1.3529 \pm 0.0001$ & $40.5327 \pm 0.0427$ \\
\hline & 0.200 & $1.0215 \pm 0.0001$ & $1.3675 \pm 0.0001$ & $60.4862 \pm 0.4783$ \\
\hline & 0.275 & $1.0325 \pm 0.0002$ & $1.3813 \pm 0.0001$ & $81.8447 \pm 0.7336$ \\
\hline & 0.350 & $1.0447 \pm 0.0001$ & $1.3963 \pm 0.0001$ & $102.2526 \pm 0.2182$ \\
\hline \multirow[t]{5}{*}{313.15} & 0.050 & $0.9983 \pm 0.0002$ & $1.3391 \pm 0.0002$ & $17.1746 \pm 1.8654$ \\
\hline & 0.125 & $1.0070 \pm 0.0001$ & $1.3520 \pm 0.0003$ & $41.2442 \pm 0.3189$ \\
\hline & 0.200 & $1.0171 \pm 0.0001$ & $1.3658 \pm 0.0001$ & $61.2896 \pm 0.2325$ \\
\hline & 0.275 & $1.0278 \pm 0.0002$ & $1.3800 \pm 0.0001$ & $82.9370 \pm 0.8661$ \\
\hline & 0.350 & $1.0397 \pm 0.0001$ & $1.3950 \pm 0.0002$ & $103.7576 \pm 0.5100$ \\
\hline \multirow[t]{5}{*}{323.15} & 0.050 & $0.9939 \pm 0.0002$ & $1.3379 \pm 0.0002$ & $18.0786 \pm 1.7400$ \\
\hline & 0.125 & $1.0025 \pm 0.0001$ & $1.3507 \pm 0.0002$ & $42.6684 \pm 0.5454$ \\
\hline & 0.200 & $1.0122 \pm 0.0002$ & $1.3644 \pm 0.0001$ & $63.3420 \pm 1.0086$ \\
\hline & 0.275 & $1.0228 \pm 0.0002$ & $1.3783 \pm 0.0001$ & $86.0201 \pm 0.6099$ \\
\hline & 0.350 & $1.0343 \pm 0.0001$ & $1.3930 \pm 0.0001$ & $107.4759 \pm 1.7396$ \\
\hline
\end{tabular}

${ }^{\mathrm{a}}$ For densities the standard uncertainty for temperature is $u(\mathrm{~T})=0.001 \mathrm{~K}$, for refractive index and electrical conductivity the standard uncertainty for temperature is $u(T)=0.11 \mathrm{~K}$. For densities, refractive index and electrical conductivity the standard uncertainty for mass fraction is $u(w)=0.0001$. Expanded uncertainties are: for density: $U c(\rho)=0.0004 \mathrm{~g} \cdot \mathrm{cm}{ }^{-3}$, for refractive index: $U c\left(n_{D}\right)=0.0011$ and electrical conductivity: $U c(\kappa)=1.72 \mathrm{mS} \cdot \mathrm{cm}^{-1}(0.95$ level of confidence $)$.
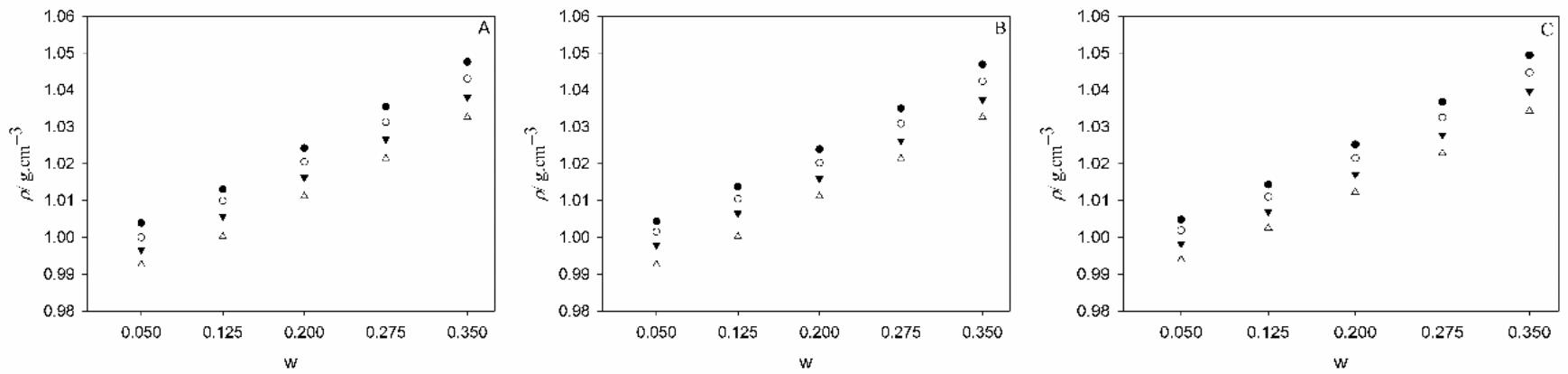

Figure 1. Density $\rho$ of binary mixtures of water + chloride, 1-ethyl-3-methyl imidazolium as a function of the mass fraction at different temperatures, $\mathrm{T} / \mathrm{K}: \bullet, 293.15 ; \circ, 303.15 ; \boldsymbol{\nabla}, 313.15 ; \Delta, 323,15$ at each value $\mathrm{pH}$ : (A) 7.5 , (B) 8.0 and $(\mathrm{C}) 8.5$. 

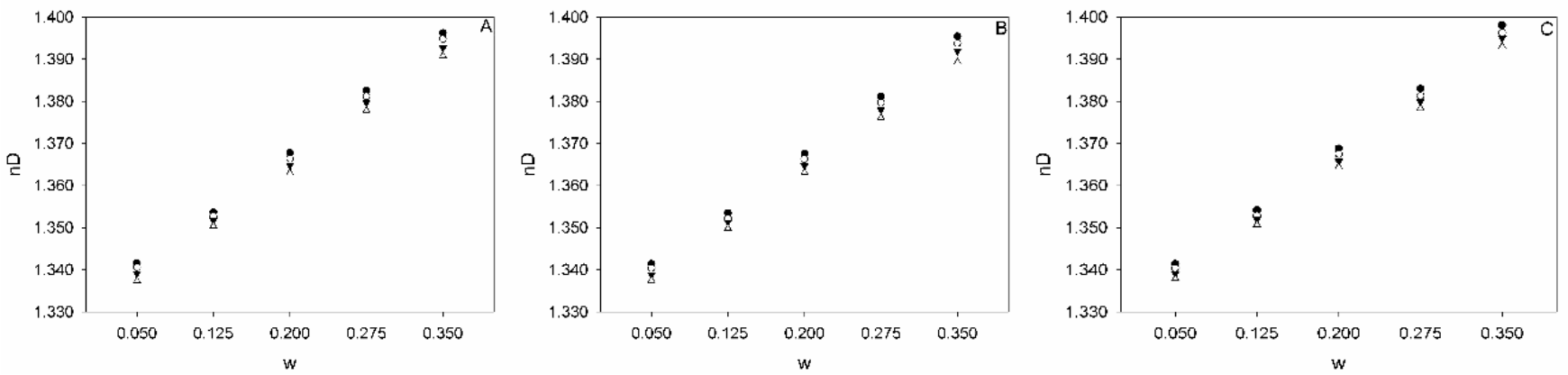

Figure 2. Refractive index $n_{D}$ of binary mixtures of water + chloride, 1-ethyl-3-methyl imidazolium as a function of the mass fraction at different temperatures, $\mathrm{T} / \mathrm{K}: \bullet, 293.15 ; \circ, 303.15 ; \boldsymbol{\nabla}, 313.15 ; \Delta, 323,15$ at each value $\mathrm{pH}$ : (A) 7.5, (B) 8.0 and (C) 8.5.
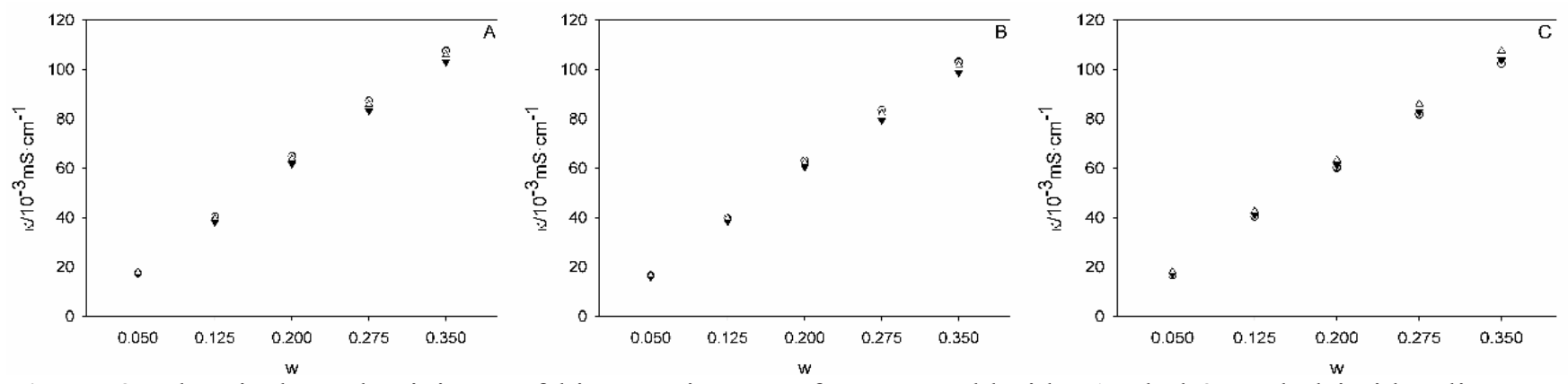

Figure 3. Electrical conductivity $\kappa$ of binary mixtures of water + chloride, 1-ethyl-3-methyl imidazolium as a function of the mass fraction at different temperatures, $\mathrm{T} / \mathrm{K}: \bullet, 293.15 ; \circ, 303.15 ; \boldsymbol{\nabla}, 313.15 ; \Delta, 323.15$ at each value $\mathrm{pH}$ : (A) 7.5, (B) 8.0 and (C) 8.5.binary mixtures of water + chloride, 1-ethyl-3-methyl imidazolium.

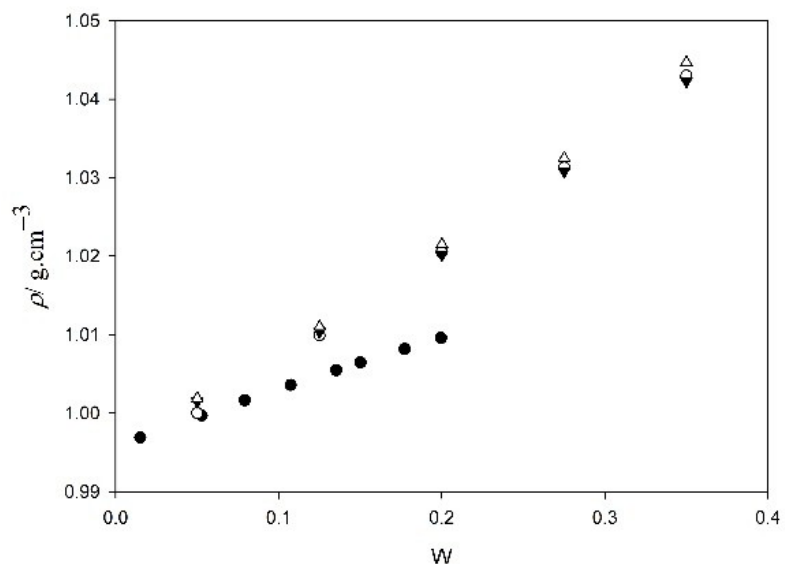

Figure 4. Comparison of measured densities for (water + 1-ethyl-3-methyl imidazolium chloride) binary system with the literature at $\mathrm{T}=303.15 \mathrm{~K}: \bullet$ (Rafie et al. (2015); Rafie et al. (2016)); this work ○, $\mathrm{pH} 7.5$; $\mathbf{\nabla}$, $\mathrm{pH} 8.0 ; \Delta, \mathrm{pH} 8.5$.

methylimidazolium chloride, temperature and $\mathrm{pH}$ values. Regarding the temperature, at constant mass fraction of 1-ethyl-3-methylimidazolium chloride, an increase in temperature causes an expansion of the liquid volume, reducing the concentration and decreasing in the refractive index of the aqueous solutions. It was also noted that the refractive index increased with increasing mass fraction of 1-ethyl-3methylimidazolium chloride. Similar behavior was observed by Tang et al. (2014), who observed that the index of refraction increased with the mass fraction of the ionic liquid.

It can be seen that the electrical conductivity increased with increasing mass fraction of 1-ethyl-3methylimidazolium chloride due to the increase in the amount of ions present in the aqueous solution (Xu et al., 2015).

From the experimental data, polynomial models were adjusted to the thermophysical properties as a function of temperature, mass fraction and $\mathrm{pH}$ of the ionic liquid by fitting the experimental data to the general model (Eq. 4), and thereby obtaining the combined effect of these properties with regards to the three variables. Non-significant parameters were eliminated based on the Student's t-test and p-value less than 0.05 .

$$
\begin{aligned}
\psi & =\beta_{1}+\beta_{2} \mathrm{w}+\beta_{3} \mathrm{~T}+\beta_{4} \mathrm{p}+\beta_{5} \mathrm{w}^{2}+ \\
& +\beta_{6} \mathrm{~T}^{2}+\beta_{7} \mathrm{p}^{2}+\beta_{8} \mathrm{w}^{3}+\beta_{9} \mathrm{~T}^{3}+\beta_{10} \mathrm{w}^{4}+ \\
& +\beta_{11} \mathrm{w} \mathrm{T}+\beta_{12} \mathrm{wp}+\beta_{13} \mathrm{Tp}+\beta_{14} \mathrm{wTp}
\end{aligned}
$$

where: $\psi$ is the thermodynamic property and $\beta_{1}, \beta_{2}, \beta_{3}$, $\beta_{4}, \beta_{5}, \beta_{6}, \beta_{7}, \beta_{8}, \beta_{9}, \beta_{10}, \beta_{11}, \beta_{12}, \beta_{13}$ and $\beta_{14}$ are constants determined from the experimental data.

Table 2 shows the coefficients obtained from the polynomial regression (Eq. 4) for density $(\rho)$, 
Table 2. Fixed parameters for the models (Eq. 4) for density $(\rho)$, refractive index $\left(n_{D}\right)$ and electrical conductivity $(\kappa)$ for binary mixtures of water +1 -ethyl3-methylimidazolium chloride.

\begin{tabular}{|c|c|c|c|}
\hline \multirow{2}{*}{ Parameters } & \multicolumn{3}{|c|}{ Properties } \\
\hline & $\rho /$ g.cm $^{-3}$ & $n_{D}$ & $\mathrm{\kappa} / 10^{-3} \mathrm{mS} \mathrm{cm}^{-1}$ \\
\hline$\beta_{1}$ & 1.0866 & 1.3739 & 1300.4804 \\
\hline$\beta_{2}$ & 0.2746 & 0.0011 & 4.0230 \\
\hline$\beta_{3}$ & -0.0003 & -0.0001 & -4.5354 \\
\hline$\beta_{4}$ & 0.0014 & $\mathrm{~ns}$ & -151.3819 \\
\hline$\beta_{5}$ & ns & 0.00001 & -0.0086 \\
\hline$\beta_{6}$ & ns & ns & 0.0052 \\
\hline$\beta_{7}$ & ns & ns & 6.2508 \\
\hline$\beta_{11}$ & -0.0004 & $\mathrm{~ns}$ & Ns \\
\hline$\beta_{12}$ & ns & ns & -0.0980 \\
\hline$\beta_{13}$ & ns & ns & 0.1690 \\
\hline $\mathrm{R}^{2}$ & 0.9966 & 0.9449 & 0.9984 \\
\hline Correlation coefficient & 0.9987 & 0.9996 & 0.9995 \\
\hline
\end{tabular}

ns: not significant. The parameters $\beta_{8}, \beta_{9}, \beta_{10}$ and $\beta_{14}$ are not in the table because they were not significant for any property.

refractive index $\left(n_{D}\right)$ and electrical conductivity $(\kappa)$. The fit between experimental and predicted data by the model was satisfactory, with $\mathrm{R}^{2}$ values and correlation coefficients greater than 0.94 .

Table 2 points to an inverse relationship for the temperature behavior for the density and refractive index. This indicates that the increase in temperature causes a decrease in these thermodynamic properties in question. The decrease of these properties with temperature is due to the increased mobility of the molecules of binary mixtures, causing a volume expansion and the decrease of intermolecular interactions (Siongco et al. 2013).

Moreover, binary mixtures had positive coefficients for the mass fraction of 1-ethyl-3-methylimidazolium chloride, confirming that the presence of the ionic liquid contributed to increasing the density and refractive index.

It can also be seen in Table 2 that the electrical conductivity was more affected by the mass fraction of 1-ethyl-3-methylimidazolium chloride than by temperature, confirming that the increase in the mass fraction of 1-ethyl-3-methylimidazolium chloride increases the electrical conductivity.
Figures 5, 6 and 7 show the data predicted by the model with regards to density, refractive index and electrical conductivity as a function of temperature and mass fraction obtained from Eq. 4 when the $\mathrm{pH}$ values were fixed. It was observed that for all thermodynamic properties the term related to temperature was negative, indicating that the three previously mentioned properties were negatively affected by the increase in this variable. In contrast, the parameter related to mass fraction was positive, indicating that there is an increase in these properties with the increase of this variable.

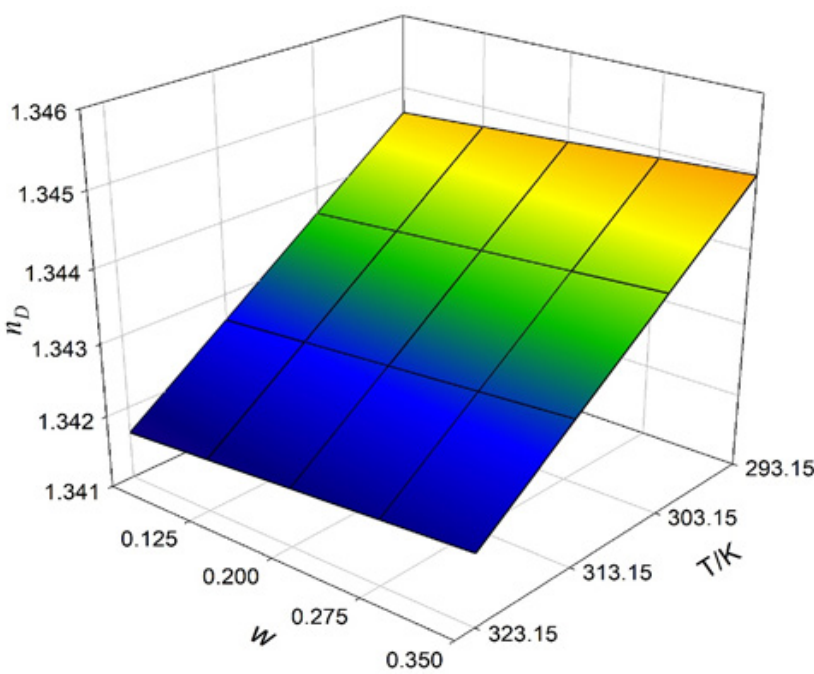

Figure 6. Refractive index $n_{D}$ of binary mixtures of water +1 -ethyl-3-methyl imidazolium chloride predicted by the model.

Apparent specific volume, molar volume and thermal expansion coefficient of the binary mixtures

From the experimental data obtained for density and from equations 1 to 3 , the properties of molar volume, thermal expansion coefficient and apparent specific volume were calculated for the binary mixtures of water + 1-ethyl-3-methylimidazolium chloride at different temperatures $\mathrm{T}=(293.15,303.15$, 313.15 and 323.15$) \mathrm{K}, \mathrm{pH}$ values $(7.5,8.0$ and 8.5$)$ and mass fraction $w=(0.05,0.12,0.2,0.275$ and 0.35$)$. The results are shown in Table 3.
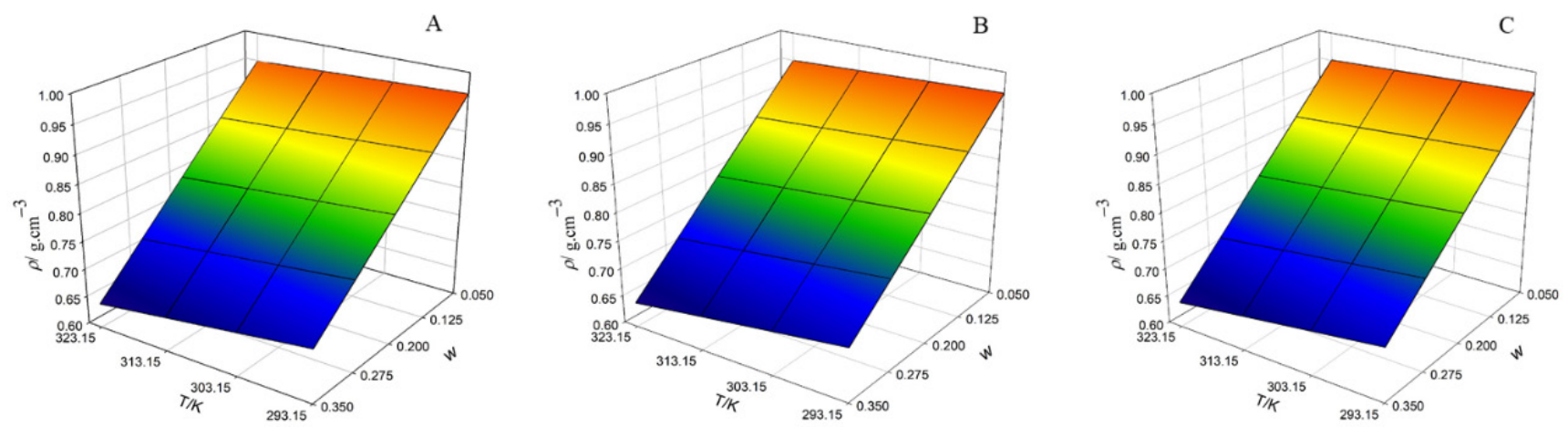

Figure 5. Density $\rho$ of binary mixtures of water +1 -ethyl-3-methyl imidazolium chloride predicted by the model at different values of $\mathrm{pH}$ (A) 7.5 (B) 8.0 and (C) 8.5. 

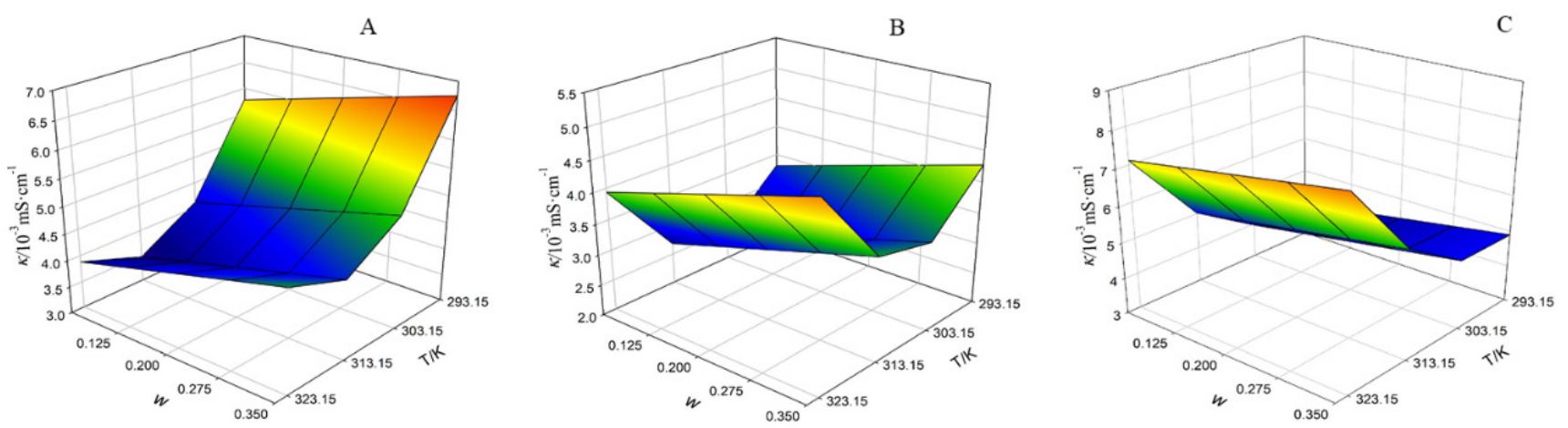

Figure 7. Electrical conductivity $\kappa$ binary mixtures of water +1 -ethyl-3-methyl imidazolium chloride predicted by the model at different values of $\mathrm{pH}$ (A) 7.5 (B) 8.0 and (C) 8.5.

Table 3. Apparent specific volume $\left(\mathrm{v}_{2 \varnothing}\right)$, molar volume $\left(V_{m}\right)$ and thermal expansion coefficient $\left(\alpha_{p}\right)$ of the binary mixtures of water +1 -ethyl-3-methylimidazolium chloride at different mass fractions $(0.05,0.12,0.2,0.275$ and $0.35)$, temperatures $\mathrm{T}=(293.15,303.15,313.15$ and 323.15$) \mathrm{K}$ and $\mathrm{pH}(7.5,8.0$ and 8.5).

\begin{tabular}{|c|c|c|c|c|}
\hline $\mathbf{T} / \mathbf{K}$ & $\mathbf{w}$ & $v_{2} \phi / g \cdot \mathbf{c m}^{-3}$ & $V_{m} / \mathrm{cm}^{3} \cdot \mathrm{mol}^{-1}$ & $\alpha_{p} / K^{-1}$ \\
\hline & & & & \\
\hline \multirow{5}{*}{293.15} & 0.050 & $0.8871 \pm 0.0009$ & $146.0508 \pm 0.0061$ & $0.3444 \pm 0.0001$ \\
\hline & 0.125 & $0.8722 \pm 0.0007$ & $144.7430 \pm 0.0116$ & $0.3416 \pm 0.0001$ \\
\hline & 0.200 & $0.8503 \pm 0.0003$ & $143.1545 \pm 0.0079$ & $0.3382 \pm 0.0001$ \\
\hline & 0.275 & $0.8354 \pm 0.0006$ & $141.5942 \pm 0.0194$ & $0.3348 \pm 0.0001$ \\
\hline & 0.350 & $0.8203 \pm 0.0014$ & $139.9591 \pm 0.0525$ & $0.3313 \pm 0.0001$ \\
\hline \multirow[t]{5}{*}{303.15} & 0.050 & $0.9163 \pm 0.0003$ & $146.6156 \pm 0.0021$ & $0.3457 \pm 0.0001$ \\
\hline & 0.125 & $0.8785 \pm 0.0003$ & $145.1814 \pm 0.0051$ & $0.3427 \pm 0.0001$ \\
\hline & 0.200 & $0.8587 \pm 0.0003$ & $143.6738 \pm 0.0083$ & $0.3394 \pm 0.0001$ \\
\hline & 0.275 & $0.8441 \pm 0.0006$ & $142.1659 \pm 0.0185$ & $0.3362 \pm 0.0001$ \\
\hline & 0.350 & $0.8292 \pm 0.0013$ & $140.5791 \pm 0.0508$ & $0.3327 \pm 0.0001$ \\
\hline \multirow[t]{5}{*}{313.15} & 0.050 & $0.9199 \pm 0.0025$ & $147.1254 \pm 0.0177$ & $0.3469 \pm 0.0001$ \\
\hline & 0.125 & $0.8878 \pm 0.0009$ & $145.7863 \pm 0.0149$ & $0.3441 \pm 0.0001$ \\
\hline & 0.200 & $0.8661 \pm 0.0004$ & $144.2804 \pm 0.0102$ & $0.3409 \pm 0.0001$ \\
\hline & 0.275 & $0.8521 \pm 0.0007$ & $142.8196 \pm 0.0228$ & $0.3377 \pm 0.0001$ \\
\hline & 0.350 & $0.8371 \pm 0.0013$ & $141.2564 \pm 0.0479$ & $0.3343 \pm 0.0001$ \\
\hline \multirow[t]{5}{*}{323.15} & 0.050 & $0.9189 \pm 0.0003$ & $147.7131 \pm 0.0023$ & $0.3483 \pm 0.0001$ \\
\hline & 0.125 & $0.9035 \pm 0.0007$ & $146.5963 \pm 0.0117$ & $0.3460 \pm 0.0001$ \\
\hline & 0.200 & $0.8744 \pm 0.0027$ & $145.0039 \pm 0.0656$ & $0.3425 \pm 0.0001$ \\
\hline & 0.275 & $0.8596 \pm 0.0010$ & $143.5481 \pm 0.0321$ & $0.3394 \pm 0.0001$ \\
\hline & 0.350 & $0.8444 \pm 0.0009$ & $141.9960 \pm 0.0335$ & $0.3361 \pm 0.0001$ \\
\hline & & & & \\
\hline \multirow[t]{5}{*}{293.15} & 0.050 & $0.8784 \pm 0.0006$ & $145.9903 \pm 0.0040$ & $0.3442 \pm 0.0001$ \\
\hline & 0.125 & $0.8661 \pm 0.0001$ & $144.6432 \pm 0.0019$ & $0.3414 \pm 0.0001$ \\
\hline & 0.200 & $0.8522 \pm 0.0003$ & $143.1995 \pm 0.0079$ & $0.3383 \pm 0.0001$ \\
\hline & 0.275 & $0.8376 \pm 0.0002$ & $141.6642 \pm 0.0074$ & $0.3350 \pm 0.0001$ \\
\hline & 0.350 & $0.8228 \pm 0.0004$ & $140.0552 \pm 0.0153$ & $0.3315 \pm 0.0001$ \\
\hline \multirow[t]{5}{*}{303.15} & 0.050 & $0.8857 \pm 0.0005$ & $146.4019 \pm 0.0033$ & $0.3452 \pm 0.0001$ \\
\hline & 0.125 & $0.8739 \pm 0.0001$ & $145.1070 \pm 0.0023$ & $0.3425 \pm 0.0001$ \\
\hline & 0.200 & $0.8605 \pm 0.0004$ & $143.7187 \pm 0.0099$ & $0.3395 \pm 0.0001$ \\
\hline & 0.275 & $0.8463 \pm 0.0004$ & $142.2377 \pm 0.0118$ & $0.3363 \pm 0.0001$ \\
\hline & 0.350 & $0.8317 \pm 0.0004$ & $140.6726 \pm 0.0149$ & $0.3330 \pm 0.0001$ \\
\hline \multirow[t]{5}{*}{313.15} & 0.050 & $0.8926 \pm 0.0008$ & $146.9351 \pm 0.0054$ & $0.3465 \pm 0.0001$ \\
\hline & 0.125 & $0.8809 \pm 0.0002$ & $145.6737 \pm 0.0027$ & $0.3438 \pm 0.0001$ \\
\hline & 0.200 & $0.8679 \pm 0.0004$ & $144.3225 \pm 0.0093$ & $0.3410 \pm 0.0001$ \\
\hline & 0.275 & $0.8540 \pm 0.0005$ & $142.8804 \pm 0.0156$ & $0.3379 \pm 0.0001$ \\
\hline & 0.350 & $0.8395 \pm 0.0004$ & $141.3466 \pm 0.0140$ & $0.3346 \pm 0.0001$ \\
\hline \multirow[t]{5}{*}{323.15} & 0.050 & $0.9020 \pm 0.0020$ & $147.5952 \pm 0.0142$ & $0.3480 \pm 0.0001$ \\
\hline & 0.125 & $0.8873 \pm 0.0002$ & $146.3333 \pm 0.0025$ & $0.3454 \pm 0.0001$ \\
\hline & 0.200 & $0.8746 \pm 0.0003$ & $145.0083 \pm 0.0080$ & $0.3426 \pm 0.0001$ \\
\hline & 0.275 & $0.8613 \pm 0.0110$ & $143.6009 \pm 0.0343$ & $0.3396 \pm 0.0001$ \\
\hline & 0.350 & $0.8465 \pm 0.0003$ & $142.0755 \pm 0.0126$ & $0.3363 \pm 0.0001$ \\
\hline
\end{tabular}

Continues on the next page 
Continued from Table 3

\begin{tabular}{|c|c|c|c|c|}
\hline $\mathbf{T} / \mathbf{K}$ & $\mathbf{W}$ & $V_{2} \phi / \mathrm{g} \cdot \mathrm{cm}^{-3}$ & $V_{m} / \mathrm{cm}^{3} \cdot \mathrm{mol}^{-1}$ & $\alpha_{p} / \mathbf{K}^{-1}$ \\
\hline & & & & \\
\hline \multirow[t]{5}{*}{293.15} & 0.050 & $0.8688 \pm 0.0040$ & $145.9903 \pm 0.0040$ & $0.3442 \pm 0.0001$ \\
\hline & 0.125 & $0.8604 \pm 0.0008$ & $144.6432 \pm 0.0019$ & $0.3414 \pm 0.0001$ \\
\hline & 0.200 & $0.8446 \pm 0.0001$ & $143.1995 \pm 0.0079$ & $0.3383 \pm 0.0001$ \\
\hline & 0.275 & $0.8300 \pm 0.0008$ & $141.6642 \pm 0.0074$ & $0.3350 \pm 0.0001$ \\
\hline & 0.350 & $0.8140 \pm 0.0001$ & $140.0552 \pm 0.0153$ & $0.3315 \pm 0.0001$ \\
\hline \multirow[t]{5}{*}{303.15} & 0.050 & $0.8765 \pm 0.0039$ & $146.4019 \pm 0.0033$ & $0.3452 \pm 0.0001$ \\
\hline & 0.125 & $0.8686 \pm 0.0005$ & $145.1070 \pm 0.0023$ & $0.3425 \pm 0.0001$ \\
\hline & 0.200 & $0.8532 \pm 0.0001$ & $143.7187 \pm 0.0099$ & $0.3395 \pm 0.0001$ \\
\hline & 0.275 & $0.8389 \pm 0.0008$ & $142.2377 \pm 0.0118$ & $0.3363 \pm 0.0001$ \\
\hline & 0.350 & $0.8231 \pm 0.0001$ & $140.6726 \pm 0.0149$ & $0.3330 \pm 0.0001$ \\
\hline \multirow[t]{5}{*}{313.15} & 0.050 & $0.8836 \pm 0.0045$ & $146.9352 \pm 0.0054$ & $0.3465 \pm 0.0001$ \\
\hline & 0.125 & $0.8760 \pm 0.0001$ & $145.6737 \pm 0.0027$ & $0.3438 \pm 0.0001$ \\
\hline & 0.200 & $0.8609 \pm 0.0002$ & $144.3225 \pm 0.0093$ & $0.3410 \pm 0.0001$ \\
\hline & 0.275 & $0.8468 \pm 0.0009$ & $142.8804 \pm 0.0156$ & $0.3379 \pm 0.0001$ \\
\hline & 0.350 & $0.8311 \pm 0.0001$ & $141.3466 \pm 0.0140$ & $0.3346 \pm 0.0001$ \\
\hline \multirow{5}{*}{323.15} & 0.050 & $0.8904 \pm 0.0048$ & $147.5952 \pm 0.0142$ & $0.3480 \pm 0.0001$ \\
\hline & 0.125 & $0.8824 \pm 0.0004$ & $146.3333 \pm 0.0025$ & $0.3454 \pm 0.0001$ \\
\hline & 0.200 & $0.8684 \pm 0.0009$ & $145.0083 \pm 0.0080$ & $0.3426 \pm 0.0001$ \\
\hline & 0.275 & $0.8536 \pm 0.0007$ & $143.6009 \pm 0.0343$ & $0.3396 \pm 0.0001$ \\
\hline & 0.350 & $0.8382 \pm 0.0001$ & $142.0755 \pm 0.0126$ & $0.3363 \pm 0.0001$ \\
\hline
\end{tabular}

${ }^{\mathrm{a}}$ For apparent specific volume, molar volume and thermal expansion coefficient the standard uncertainty for temperature is $u(\mathrm{~T})=0.001 \mathrm{~K}$ and for mass fraction is $u(w)=0.0001$. Expanded uncertainties are for apparent specific volume: $U c\left(\mathrm{v}_{2 \emptyset}\right)=0.002 \mathrm{~g} \cdot \mathrm{cm}^{-3}$, for molar volume: $U c\left(V_{m}\right)=0.6508 \mathrm{~cm}^{3} \cdot \mathrm{mol}^{-1}$ and for thermal expansion coefficient: $U c\left(\alpha_{p}\right) 0.0020$ $=\mathrm{K}^{-1}(0.95$ level of confidence $)$.

The molar volume, thermal expansion coefficient and apparent specific volume of the binary mixtures of water + 1-ethyl-3-methylimidazolium chloride decreased with an increase in mass fraction and increased with an increase in temperature.

Similar behavior for the apparent molar volume was found by Rafie et al. (2015) studying the ionic liquid, 1-ethyl-3-methyl imidazolium chloride in aqueous lithium nitrate, lithium bromide, and lithium chloride solutions at temperatures 298.15 to $318.15 \mathrm{~K}$.

Using the same procedures as above, polynomial models were fit to the properties of molar volume, thermal expansion coefficient and apparent specific volume of the binary mixtures as a function of temperature, mass fraction and $\mathrm{pH}$ of the ionic liquids, by fitting the experimental data to the general model (Eq. (4)). Table 4 shows the coefficients obtained from the polynomial regression (Eq. 4) for the properties of apparent specific volume $\left(\mathrm{V}_{2 \varnothing}\right)$, molar volume $\left(\mathrm{V}_{\mathrm{m}}\right)$ and thermal expansion coefficient $\left(\alpha_{p}\right)$.
Figures 8,9 and 10 show the data predicted by the model with respect to specific volume, molar volume and thermal expansion coefficient as a function of

Table 4. Fixed parameters of the models (eq. 4) for apparent specific volume $\left(\mathrm{v}_{2 \varnothing}\right)$, molar volume $\left(V_{m}\right)$ and thermal expansion coefficient $\left(\alpha_{p}\right)$ for the binary mixtures of water + 1-ethyl-3-methylimidazolium chloride.

\begin{tabular}{cccc}
\hline \multirow{2}{*}{ Constants } & \multicolumn{3}{c}{ Properties } \\
\cline { 2 - 4 } & $\mathbf{V}_{\mathbf{2} \boldsymbol{Q}} / \mathbf{g} \cdot \mathbf{c m}^{\mathbf{- 3}}$ & $\mathbf{V}_{\mathbf{m}} / \mathbf{c m}^{\mathbf{3}} \cdot \mathbf{m o l}^{-\mathbf{1}}$ & $\boldsymbol{\alpha}_{\mathbf{p}} / \mathbf{K}^{-\mathbf{1}}$ \\
\hline$\beta_{1}$ & 0.8764 & 131.8090 & 0.3040 \\
$\beta_{2}$ & -0.0082 & -0.3314 & -0.0004 \\
$\beta_{3}$ & 0.0008 & 0.0520 & 0.0001 \\
$\beta_{4}$ & -0.0276 & $\mathrm{~ns}$ & $\mathrm{~ns}$ \\
$\beta_{11}$ & $\mathrm{~ns}$ & 0.0005 & $\mathrm{~ns}$ \\
$\beta_{12}$ & 0.0008 & $\mathrm{~ns}$ & $\mathrm{~ns}$ \\
$\mathrm{R}^{2}$ & 0.9751 & 0.9978 & 0.9950 \\
Correlation coefficient & 0.9907 & 0.9993 & 0.9991 \\
\hline
\end{tabular}

ns: not significant. The parameters $\beta_{5}, \beta_{6}, \beta_{7}, \beta_{8}, \beta_{9}, \beta_{10}, \beta_{13}$ and $\beta_{14}$ are not in the table because they were not significant for any property.
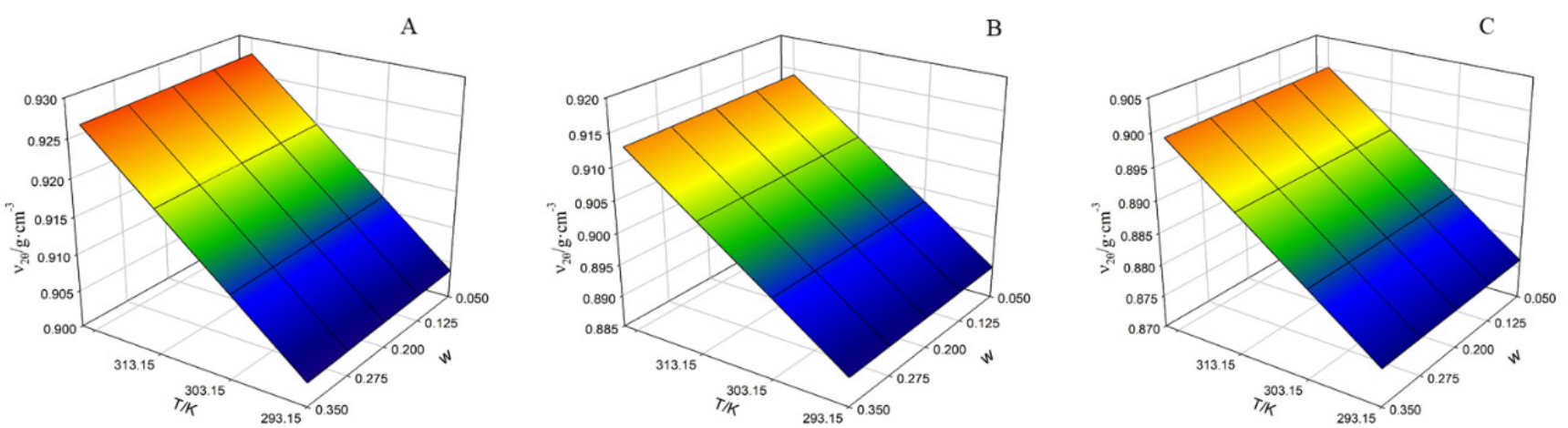

Figure 8. Specific volume $v_{2 \varnothing}$ of binary mixtures of water +1 -ethyl-3-methyl imidazolium chloride predicted by the model at different values of $\mathrm{pH}$ (A) 7.5 (B) 8.0 and (C) 8.5. 


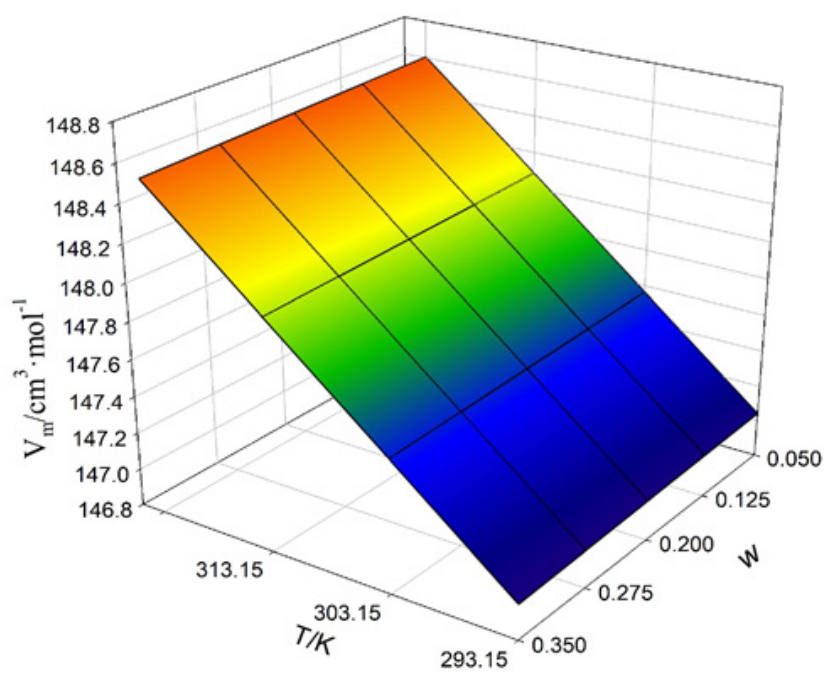

Figure 9. Molar volume $V_{m}$ of binary mixtures of water + 1-ethyl-3-methyl imidazolium chloride predicted by the model.

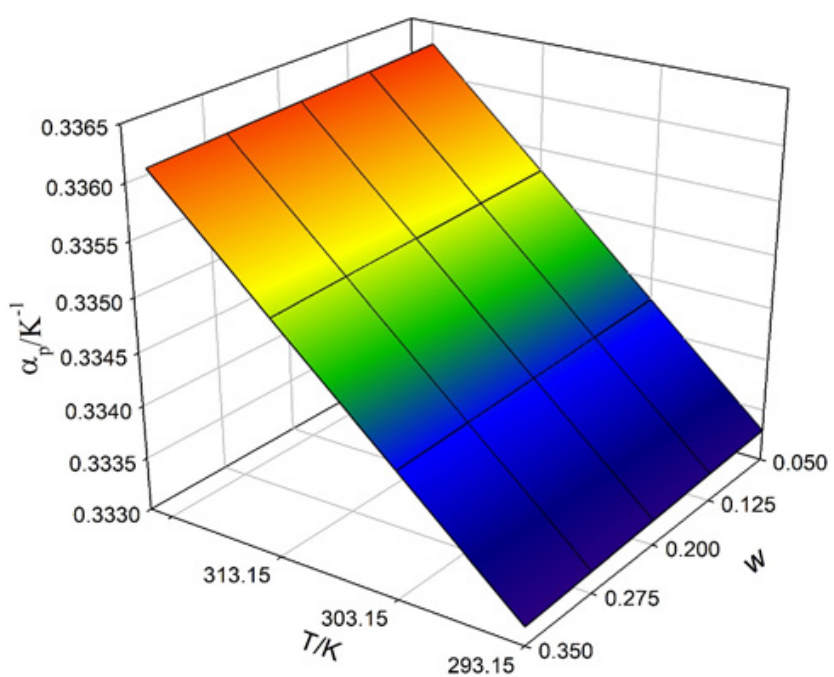

Figure 10. Coefficient of thermal expansion $\alpha_{p}$ of binary mixtures of water +1 -ethyl-3-methyl imidazolium chloride predicted by the model.

the temperature and mass fraction obtained from eq. 4 , in which the $\mathrm{pH}$ was fixed for each value. It can be observed in the figures that the values of these 3 properties decreased as the mass fraction increased and increased with increases in temperature.

\section{CONCLUSION}

It was possible to obtain experimental data for the properties density $(\rho)$, electrical conductivity $(\kappa)$ and refractive index $\left(n_{D}\right)$, under various conditions of temperature, mass fraction and $\mathrm{pH}$ of aqueous solutions of the ionic liquid. From the experimental data for the density it was possible calculate the apparent specific volume $\left(\mathrm{v}_{2 \varnothing}\right)$, the coefficient of thermal expansion $\left(\alpha_{p}\right)$ and molar volume $\left(V_{m}\right)$. Polynomial models for the properties presented satisfactory fits to the experimental data. The results were satisfactory and can be used for the design and scale up of separation process under such experimental conditions.

\section{NOMENCLATURE}

\begin{tabular}{|c|c|}
\hline W & mass fraction \\
\hline $\mathrm{T}$ & temperature, $\mathrm{K}$ \\
\hline ILs & ionic liquids \\
\hline ATPS & two-phase aqueous systems \\
\hline$\left(\left[\mathrm{C}_{2} \mathrm{mim}\right] \mathrm{Cl}\right)$ & $\begin{array}{l}\text { 1-ethyl-3-methylimidazolium } \\
\text { chloride }\end{array}$ \\
\hline$P$ & density, $\mathrm{g} \cdot \mathrm{cm}^{-3}$ \\
\hline$V_{m}$ & molar volume, $\mathrm{cm}^{3} \cdot \mathrm{mol}^{-1}$ \\
\hline$\alpha_{\mathrm{p}}^{m}$ & thermal expansion coefficient, $\mathrm{K}^{-1}$ \\
\hline $\mathrm{v}_{2 \varnothing}^{\mathrm{p}}$ & apparent specific volume, $\mathrm{cm}^{3} \cdot \mathrm{g}^{-1}$ \\
\hline$n_{D}$ & refractive index \\
\hline $\mathrm{K}$ & electrical conductivity, $\mathrm{mS} \cdot \mathrm{cm}^{-1}$ \\
\hline CRD & completely randomized design \\
\hline$\psi$ & thermophysical property \\
\hline$\beta$ & adjusted parameter \\
\hline $\mathrm{R}^{2}$ & correlation coefficient \\
\hline
\end{tabular}

REFERENCES

Dreyer, S., Salim, P. and Kragl, U., Driving forces of protein partitioning in an ionic liquid-based aqueous two-phase system, Biochemical Engineering Journal, 46(1), 176-185 (2009). https://doi. org/10.1016/j.bej.2009.05.005

Du, Z., Yu, Y.L. and Wang, J.H., Extraction of proteins from biological fluids by use of an ionic liquid/aqueous two-phase system, Chemistry A European Journal, 13(7), 2130-2137 (2007). https://doi.org/10.1002/chem.200601234

Fadeev, A.G. and Meagher, M.M., Opportunities for ionic liquids in recovery of biofuels, Chemical Communications, 2011(3), 295-296 (2011). https:// doi.org/10.1039/b006102f

Ferreira, A.M., Coutinho, J.A.P., Fernandes, A.M. and Freire, M.G., Complete removal of textile dyes from aqueous media using ionic-liquidbased aqueous two-phase systems. Separation and Purification Technology, 128, 58-66 (2014). https:// doi.org/10.1016/j.seppur.2014.02.036

Ficke, L.E., Novark, R.R. and Brennecke, J.F., Thermodynamic and Thermophysical Properties of Ionic Liquid + Water Systems, Journal of Chemical and Engineering Data, 55 (11), 4946-4950 (2010). https://doi.org/10.1021/je100522z

França, J.M.P., Nieto de Castro, C.A., Lopes, M.M. and Nunes, V.M.B., Influence of Thermophysical Properties of Ionic Liquids in Chemical Process Design. Journal of Chemical and Engineering Data, 54(9), 2569-2575 (2009). https://doi.org/10.1021/ je $900107 \mathrm{t}$ 
Huddleston, J.G., Willauer, H.D., Swatloski, R.P., Visser, A.E. and Rogers, R.D., Room temperature ionic liquids as novel media for 'clean' liquid-liquid extraction. Chemical Communications, 1998(16), 1765-1766 (1998). https://doi.org/10.1039/ A803999B

Muhammad, N., Man, Z., Ziyada, A.K., Bustam, M.A., Abdul Mutalib, M.I., Wilfred, C.D.; Rafiq, S. and Mohd Tan, I., Thermophysical Properties of Dual Functionalized Imidazolium- Based Ionic Liquids, Journal of Chemical and Engineering Data, 57(3), 737-743 (2012). https://doi.org/10.1021/je200710t

Muray, S.M., Zimlich, T.K., Mirjafari, A., O’Brien, R.A. and Davis, J.H., Thermophysical Properties of Imidazolium-Based Lipidic Ionic Liquids, Journal of Chemical and Engineering Data, 58(6), 15161522 (2013). https://doi.org/10.1021/je301004f

Rafie, H.R., Frouzesh, F. Study of Apparent Molar Volumes for Ionic Liquid, 1-Ethyl-3-methyl Imidazolium Chloride in Aqueous Lithium Nitrate, Lithium Bromide, and Lithium Chloride Solutions at Temperatures (298.15 to 318.15 ) K. Journal of Chemical and Engineering Data, 60, 2958-2965 (2015). https://doi.org/10.1021/acs.jced.5b00329

Rafie, H.R., Frouzesh, F. Volumetric properties of ionic liquids, 1-Ethyl-3-ethylimidazolium chloride [Emim] $[\mathrm{Cl}]$ and 1-Ethyl-3-methylimidazolium hydrogen sulfate [Emim] [HSO $]$ in sucrose aqueous solutions at $\mathrm{T}=(293.15-313.15) \mathrm{K}$ and ambient pressure. Fluid Phase Equilibria, 425, 120-126 (2016). https://doi.org/10.1016/j.fluid.2016.05.024

Ribeiro Júnior, J. I. Análises estatísticas no SAEG, UFV, Viçosa. 2001. 301 p.

Sampaio, V.S., Bonomo, R.C.F., Veloso, C.M., Sousa, R.C.S., Júnior, E.C.S., Fontan, únior, E.C.S., Fontan, R.C.I., Pignata, M.C., Santos, K.A., Gandolfi, O.R.R., Partitioning Behavior of Lysozyme and $\alpha$-lactalbumin in aqueous two-phase system formed by ionic liquids and potassium phosphate, International Journal of Food Engineering, 13(10), (2017). https://doi.org/10.1515/ijfe-2017-0274

Siongco, K.R., Leron, R.B. and Li, M.-H., Densities, refractive indices, and viscosities of N,Ndiethylethanol ammonium chloride-glycerol orethylene glycol deep eutectic solvents and their aqueous solutions., The Journal of Chemical Thermodynamics, 65, 65-72 (2013). https://doi. org/10.1016/j.jct.2013.05.041

Tang, J., Li, S., Zhai, Q., Jiang, Y. and $\mathrm{Hu}, \mathrm{M}$. Measurements and correlations of the solid-liquid equilibrium of $\mathrm{RbCl} / \mathrm{CsCl}+\left[\mathrm{C}_{\mathrm{n}} \mathrm{mim}\right] \mathrm{Cl}(\mathrm{n}=2,4$, $6,8)+\mathrm{H}_{2} \mathrm{O}$ ternary systems at $\mathrm{T}=(288.15,298.15$, and 308.15) K. Journal of Chemial and Engineering Data, 59, 726-735 (2014). https://doi.org/10.1021/ je4007986

Vicente, F.A., Malpiedi, L.P., Silva, F.A., Jr. Pessoa, A., Coutinho, J.A.P. and Ventura, S.P.M., Design of movel aqueous micellar two-phase systems using ionic liquids as co-surfactants for the selective extraction of (bio) molecules. Separation and Purification Technology, 135, 259-267 (2014). https://doi.org/10.1016/j.seppur.2014.06.045

Xu, L., Cui, X., Zhang, Y., Feng, T., Lin, R., Li, X. and Jie, H., Measurement and correlation of electrical conductivity of ionic liquid [EMIM][DCA] in propylene carbonate and $\gamma$-butyrolactone. Electrochimica Acta, 174, 900-907 (2015). https:// doi.org/10.1016/j.electacta.2015.06.053

Yan, J.K., Ma, H.L., Pei, J.J., Wang, Z.B. and Wu, J.Y., Facile and effective separation of polysaccharides and proteins from Cordyceps sinensis mycelia by ionic liquid aqueous two-phase system. Separation and Purification Technology, 135, 278-284 (2014). https://doi.org/10.1016/j.seppur.2014.03.020 